\title{
Social Media by Indian Universities-Does it convince or confuse International Students in University Choice?
}

\author{
Vikram Kumar ${ }^{1} \&$ Ramakrishnan $\operatorname{Raman}^{1}$ \\ ${ }^{1}$ Symbiosis International (Deemed University) \& Symbiosis Institue of Business Management, Pune, India \\ Correspondence: Ramakrishnan Raman, Symbiosis International (Deemed University) \& Symbiosis Institue of \\ Business Management, Pune, India.
}

Received: June 292020

Accepted: July 18, 2020

Online Published: July 21, 2020

doi:10.5430/ijhe.v9n5p167

URL: https://doi.org/10.5430/ijhe.v9n5p167

\begin{abstract}
The advent of information and communications technology has changed the way people and organisations function, communicate, transact, recruit, market business and services. To keep pace with the ever-changing business and marketing trends, organisations have integrated information, tools of communication \& the boom of internet technology into their strategies.

The education industry is no exception to this challenge. The primary goals in marketing University is to attract prospective students from across the globe. Increasing globalisation, aspiration, movement, ease of financial access is drawing students to apply for higher studies in Universities away from their country of residence. Many new-age studies of youth, teenagers and Gen Y overwhelmingly suggest that they are prolific users of the Internet and in particular social media applications. These factors have led to social media being heavily leveraged by universities to create interest and draw in applicants. Social media tools like Facebook, Instagram, LinkedIn, Quora, Google+, Youtube is integrated with the other traditional media viz print/broadcast media, exhibitions, educational trade fairs et al to reach students from various countries. Social Media plays dual power of attracting student applicants as well as helps engagement to create a loyal online community through sharing content which is found relevant and useful by the new young generation.

This research paper examines the role of social media in helping international students choose university for higher studies in India. This study included in-depth interviews and a survey to include 183 students' International students studying in 6 different cities in India.

The research findings indicate that International Students increasingly use social media thus highlighting the role of social media in influencing international students' choice of university. All in all, this study provides directions for universities to influence students innovatively and strategically. International students depend on social media for supplementary information to strengthen the information gathered through primary influencers like family, friends and alumni.

With increasing media clutter it's absolutely essential to ensure media planning for use of social media sharp and appropriate media tools are selected to reach the students and thereby enable them to effectively use it for choice of University. Social media strategy through consumer generated word of mouth and influencer marketing to communicate the experience, safety, acceptance of diverse culture can be leveraged to help the students' choice process.
\end{abstract}

Keywords: international students, university, social media, choice, higher studies, India

\section{Introduction}

The advent of information and communications technology has changed the way people and organisations function, communicate, transact, recruit, and conduct business. To keep pace with the ever-changing business and marketing trends, organisations have integrated information, tools of communication \& the boom of internet technology into their association with leadership tasks such as production and marketing strategies. The rate of innovation and adaptation of social media has influenced organisations to discover effective and sustainable ways to communicate with their existing consumer base as well prospective audiences.

The education industry is no exception to this challenge. Many new-age studies of youth, teenagers and Gen $\mathrm{Y}$ 
overwhelmingly suggest that they are prolific users of the Internet and in particular social media applications. As future prospective students for higher studies, they are likely to prefer social media applications such as Facebook, Twitter, Google+, to seek interactive and engaging university course information.

The impact of social media and Internet technology on people's buying behavior and decision making pressured educational institutions to adopt new trends and become more responsive to queries and leads posted by applicants. However, universities face a number of issues and challenges in the development and implementation of their marketing goals and strategies. Some of these issues and challenges include lack of knowledge of and expertise in the use of social media as a marketing tool, poor Internet-based marketing techniques, the expanding complexity of marketing and recruitment strategies and practices, the fast evolving social media, the changing decision-making and communication choices and processes of potential students using new devices and social media platforms and applications.

The fleeting efflux of the internet gave way to a fast-paced adoption rate of social media not just as a tool used for information and entertainment but also as means of building a lifestyle around it - thus contributing to the formation of a digital community brought together by the common denominator - their love for the internet. Networking sites like Facebook, Twitter and Instagram, blog sites, hosted services, content streaming sites (e.g., YouTube, Amazon Prime, Netflix, etc.), and web applications, among others, started blooming. The most popular social network site in Europe is Facebook with at least $62 \%$ registered users. It was also found that while 94 percent of Americans still use personal computers for social media use, the use of other new devices such as smartphones and tablets are increasing. Globally, the total number of mobile subscribers reached 6.5 billion in 2012(2012).

These recent statistics regarding new technological developments continue to press educational institutions to discover new ways and techniques to communicate with and to attract prospective students in various countries. Larger educational institutions in various countries do not compete for mere potential students; they compete for the best and brightest individuals from across the globe. Most American universities have seen the unlimited potential of social media and Social media in connecting with and recruiting international students. These well-known universities that have been using social media (2012) include Yale University, University of Rochester, John Hopkins University, University of Oregon, Harvard University, and Princeton University (Social Media Week, 2012). Morris (2012) suggested that social media is used by international students to assist in the university

decision making process. This is supported by Levitz (Thorton, 2017) who observed that $46 \%$ of prospective students visited a college's Facebook page and 69\% "liked" a college's page. Therefore, Constantinides \& Zinck Stagno (2011) stated that it is social media which encourages a culture of participation, engagement and collaboration, has a high potential to be used by universities to increase visibility and attract more students.

Most prior studies have been country and faculty specific, but not on international students as a whole. Therefore the problem statement of this study is: Whilst social media appears to have much promise and potential, it is still to be empirically determined whether and what role social media plays in international students' decision of university and course. This statement of the problem does not merely require the investigation of international students' social media use, activities and preferences, but also social media marketing techniques that may be used and applied by universities. Thus, this research focuses on the relationship between international students' social media usage with their university decision-making processes. The secondary research questions are as follows:

1. What social media do international students use to search for a university or course?

2. Which social media sites influence international students' university decision-making process?

3. What are the international students' social media usage and preference?

4. What are the social media sites and channels that can be used by universities to recruit and attract international students?

\section{Literature Review}

Efficient international student recruitment relies on an in-depth view of what students want to major in and the location in which they would like to pursue their higher education.

The UNESCO Institute of Statistics (n.d.) defines international or internationally mobile students as "students who have crossed a national or territorial border for the purpose of education and are now enrolled outside their country of origin." On the other hand, the OECD (2003) defines international students as "persons admitted by a country other than their own, usually under special permits or visas, for the specific purpose of following a particular course of study in an accredited institution of the receiving country. International students are students who do not hold the 
citizenship of the country for which the data are collected."

While the William Paterson University reflects on the definition of an international student as provided by UNESCO, University of Southern California has updated their definition to state "USC defines an international student as anyone who is not a citizen or permanent resident of the United States. American citizens who reside in other countries and attend foreign schools are not considered international students."

Universities need to develop novel ways to attract international students as admitting these stands as a priority. The intense environment of global competition along with budget cuts amongst the universities poses a challenge and forces them to shift their focus on international student recruitment (Choudaha \& Chang, 2012). Moreover, digitalisation brings with it a foresight to involve a number of more inclusive recruitment activities - one of them involving social media. International student mobility and study destinations, India as preferred destination by International students

The Ministry of External Affairs (MEA) under the Government of India has rolled out an ambitious "Study in India" program for internal students in order to boost the diversity and tenacity in booming college/university campuses in India. A division under the "Make in India" also brought together by Skill India campaign (2018) launched by current Prime Minister Narendra Modi's government aimed to quadruple the number of international students from 46,000 to 2 lakhs by the year 2023 .

The government proposed to set aside a budget of 150 crore Rupees to facilitate and implement the scheme in question. The objectives of this scheme will not only be limited to positioning India as a favourable destination for availing quality higher education, but also help build stronger diplomatic relations with neighbouring countries - the students of which are being targeted as potential applicants. This will not only help bring out the sustainable culture of India as an upcoming metropolitan country but also increase the inflow of inbound applicants that would contribute to systematic brand building.

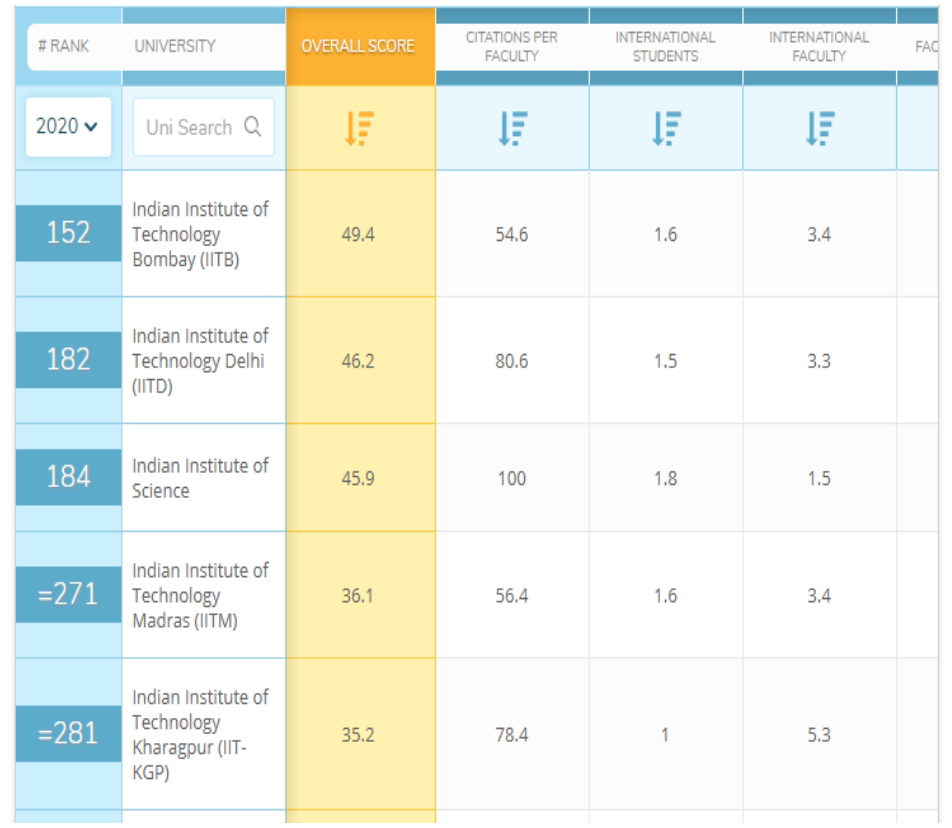

Figure 1.Rank of Institutions 2020

As observed in the QS World University Rankings for 2020, Indian universities start to show up only after the top 150 universities in the world. Indian Institute of Technology (IIT-Bombay) ranks 152, followed by IIT-Delhi at 185 and Indian Institute of Science (IISc-Bangalore) at 184. This shows that to make India one of the top ranking destinations for educational migration, we still have a long way to go.

The perceived limitations in these premier universities in India come from a variety of reasons: selectivity being one. It is observed that because Indian universities are extremely selective and have very high entry standards, very few students are eligible out of which most get accepted into MIT, CalTech or Stanford. Those who would wish to apply to India over and above this drawback are not satisfied with the quality of infrastructure, facilities and the negative perception of security as well as reputation of the Indian higher education industry. Thus all in all, an entire revamping 
process of how Universities are looked at in India is required if the goals defined by "Study in India are to be met with by the year 2023. International Student Data - Mobility and Accessibility.

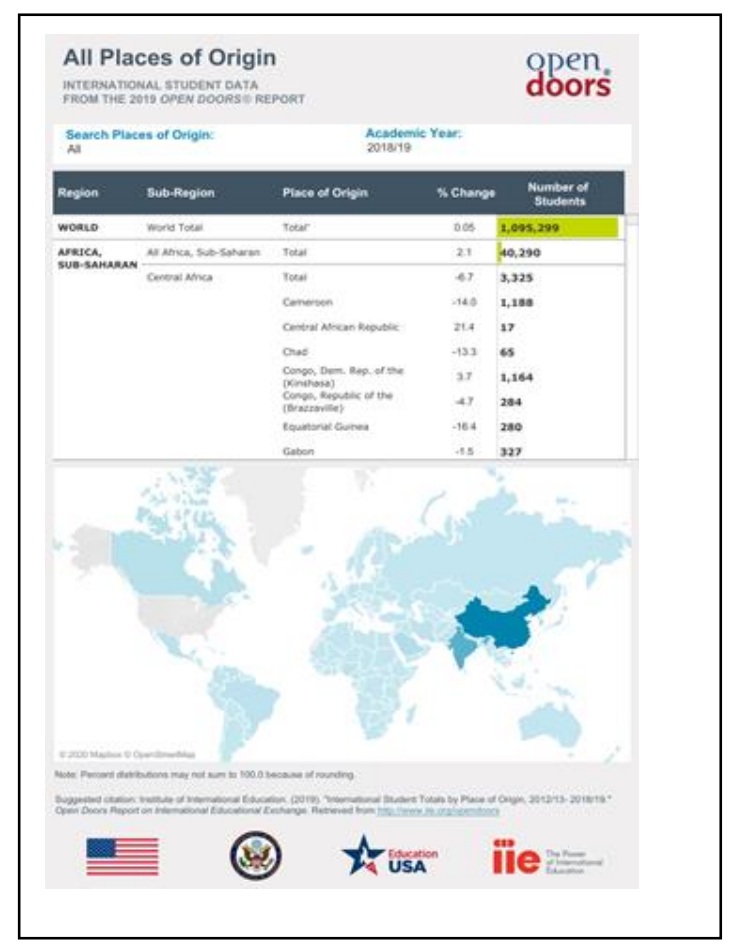

Figure 2. Factors that influence international students' to study in India

Education in the modern world not only remains a way of acquiring knowledge and expertise but also supplements in creating a professional environment which can also be argued to be brand building. Choosing a university is a critical decision to make as it serves as an integral part of a student's academic, professional and personal lives. The common factors that affect this decision include financial aspects of the overall education, the disciplines they wanted to pursue, the consequential benefits of the pursuing the said course, demography, general weather and finally look for the availability of such a course.

Some of the push factors, according to Phang (2013), include the potential applicant's perception of a higher quality higher education system in foreign lands; lack of access to quality, good local higher education and availability or presence of technology-based higher education programs. On the other hand, the pull factors that encourage international students to pursue higher education abroad (Phang, 2013; Maringe, 2006; Mazzarol \& Soutar, 2002; Maringe \& Carter, 2007; Pimpa, 2003) include the geographic propinquity of the host nation (e.g., a Canadian or Mexican citizen who wants to study in the U.S.); language commonality and opportunity to enhance second language; the higher education institution's reputation for quality; teaching personnel's credential, qualification and reputation; availability of courses and programs; and the institution's effective recruitment and marketing campaigns.

Other aspects that might play a pivotal role in the process of selecting a university are the resident nation's image or reputation along with the current affairs of the said nation, multicultural values, safety and security, a liberalized immigration process, prioritized visa applications, quality university environment conducive to learning and last but not the least, good facilities that make for a hospitable stay for the student.

Some of the foremost factors that influence choice of University for higher education is secured future, better career growth opportunities, higher probability of return on investment.

Moreover, the ethenic origins and social backgrounds of the applicant have also been found to influence the various aspects of the sedicion making process including their behaviour, perceptions and beliefs (Zhou \& Zang). 


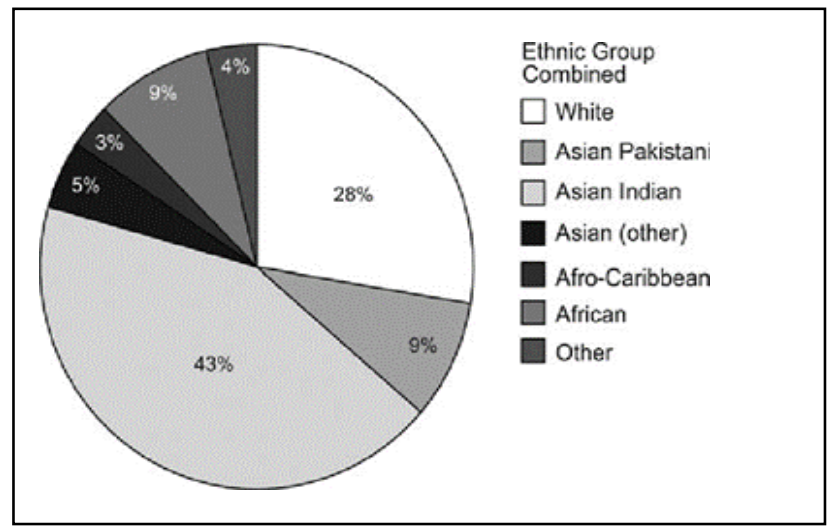

Figure 3. Representation of Diversity in International Students

For example, Asian Indian students are perceived to be affected by the social factors such as peers, society's norms, etc on the other hand Afro-Caribbean students are affected by being able to secure a stable future, better employment opportunities. In the case of Chinese students the most affluent motivator is the one child policy where the parents want to provide the best available education to their only child. More common motivators are the student's beliefs, aspirations, broaden personal experience, learn new cultures and higher standard of living. An interesting finding also reports that many students consider international prospects for studying to hold proficiency over English language.

\section{University Choice \& Decision-making: Definition \& Theoretical models}

Decision-making is defined as "the act of choosing one alternative from a set of alternatives"(Bruce, Davis, Hughes, Partridge, \& Stoodley, 2014). However, according to Griffin (2007) the process of choice and decision-making "includes recognizing and defining the nature of a decision situation, identifying alternatives, choosing the best alternative, and putting it into practice." The definition by Giffin (2007) is highly pertinent to the context of higher education.

The decision-making process of universities and courses has been affected over the years by several characteristics at the pre-selection and quest periods. Traditional sources of knowledge such as brochures, educational exhibits, web pages, influence of parents, colleagues, and peers were dominant. The emergence of social media today provides in a particular manner another means of knowledge for university and course discovery and decision-making - by cooperation, networking, and engagement with the world.

Several theoretical models explain the various factors that influence the student's intentions to pursue their education in a certain university.

Theoretical Models for Decision Making (A flowchart)

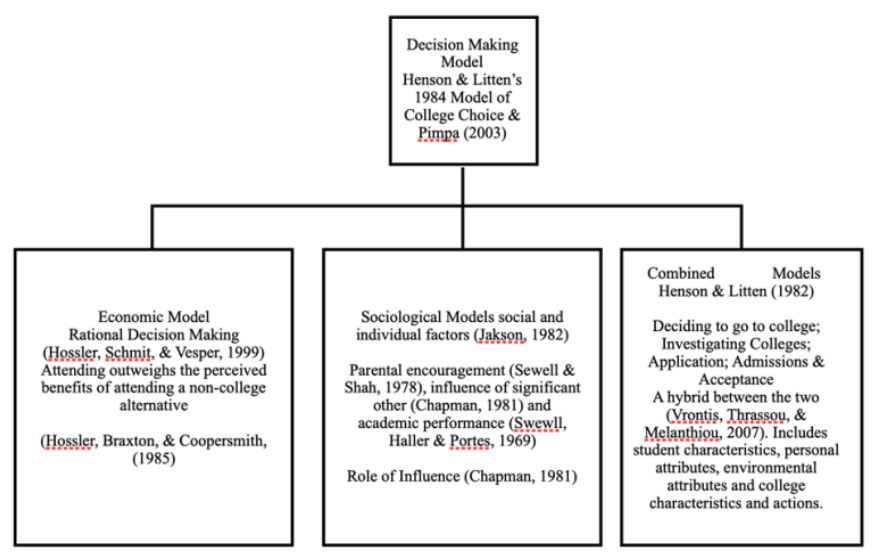

Figure 4. Model of International Students' Preferences

From the perspective of an applicant there are numerous facets that contribute to the shortlisting of a certain university. These variables include availability of expert advice, industry exposure, flexibility available in the course 
structure, openness to accommodation of students with multicultural backgrounds.

Students' final decision lies on their evaluation of the overall finances and costs along with considering all their financial options. Hence, promptness and quality communication becomes of utter importance as students seek to enroll in the best university or programme available in their discipline of interest (Cubillo, Sánchez, \& Cerviño, 2006).

Model of International Students' Preferences

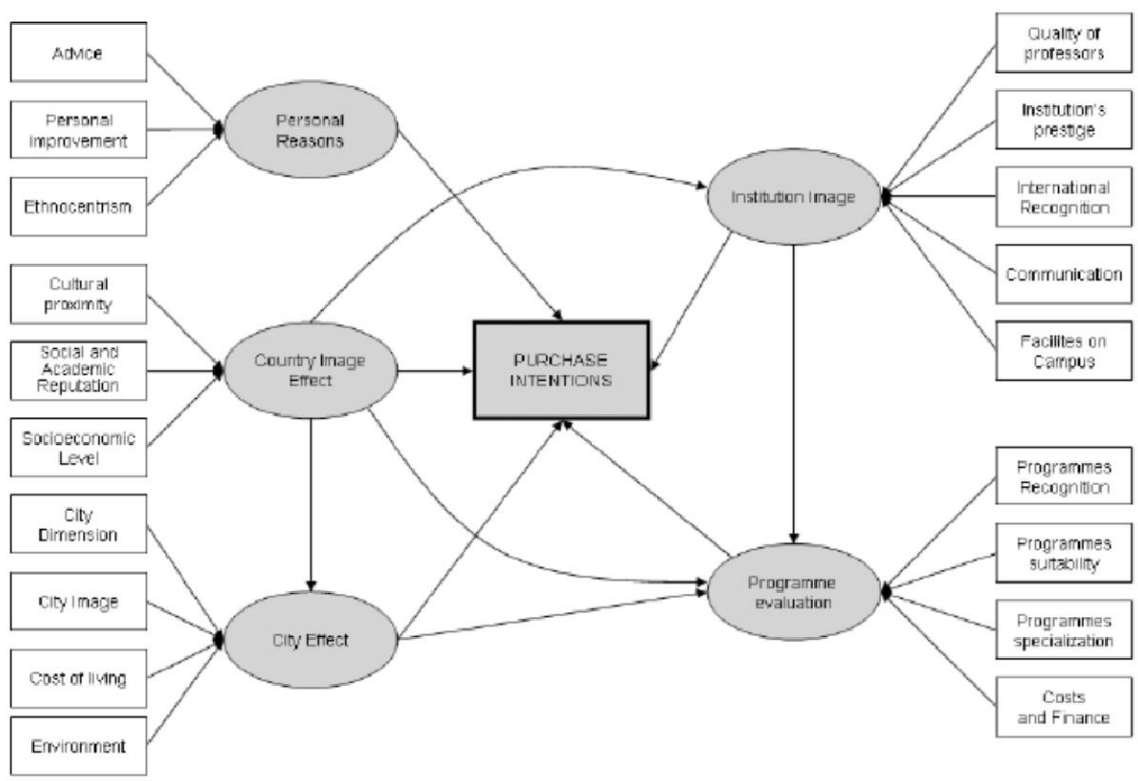

Figure 5. Source: Cubillo, Sanchez, \& Cervino, (2006, p.7)

According to (Chapman, 1986), the students go through five important and distinct stages that can be defined as follows - "Pre-Search Behavior, Search Behavior, Application Decision, Choice Decision, Matriculation Decision" India and International students : The government ambitious target to attract 200,000 foreign students to India, more than four times the current number is part of a "Study in India" scheme launched jointly by four ministries-HRD (Human Resource Development), external affairs, home and commerce. From easing the visa process to giving a sizable fee waiver to foreign students from Asia and Africa, the scheme marks a concerted effort to make Indian campuses diverse and inclusive to attract International students.

\section{Social Media}

The essential features of social media include presence, identity, relationship building, community, conversation, sharing ad reputation (Thomson, 2008). Consequently, the mere development of social media has fundamentally changed the way business is conducted by any kind of institution (Qualman, 2010). Popular social media platform like Facebook, Twitter, LinkedIn, Instagram, etc are used widely and to full advantage to employ various marketing and social media strategies to reach out more international students at every moment. The various advantages to social media as a form of digital marketing are Cost effective, Instantaneous feedback, Measurable, Easily accessible tools, High conversion ratesThe increased usage of the internet as a form of media is extremely influential in today's times. The educational sector is completely revolutionized considering that the majority of the student population are ardent users of the internet. This has a direct implication in terms of penetration, reach and effective communication with prospective, current and graduated students so as to integrate the entire community.

In order for consumer marketing on social media to be made effective, it has to be determined if the target consumer is open to technology to a certain degree. This parameter, defined as Consumer Technology Readiness can be explained as "people's propensity to embrace and use new technologies for accomplishing goals at home and during work" (Parasuraman, 2000). CTR is an important element to pay heed to when brands are exploring channels of communication and penetration pertaining to their consumers - to be able to gauge if social media as a tool of reaching out to the prospective as well as current customers will be as effective in the respective market. An aspect of the tool that social media claims to be in the marketing sphere, is the Virtual Brand Community frontier, or a VBC. Defined as the characteristics of consumers that build a common interest and thus form a community of their own via online media 
to be able to connect with each other as an aggregate(Brodie, Ilic, Juric, \& Hollebeek, 2013) has redefined the boundaries of creation and consumption of the said interests - be it brands, products or services. Casaló, Favián and Guinalíu (2008) originated the idea that the more a member trusts a VBC, the more their participation in the said VBC increases - and a higher rate of participation experience indicates higher consumer brand loyalty. Thus, brand faith aka trust is a central aspect to endure VBC (Casaló, Flavián, \& Guinalíu, 2008).

Within these VBC's there has been a development, defined as eCCI: "Electronic Consumer to Consumer Interaction" which in simple language means the interaction between two or more users of the electronic media services (Paquette, 2013) Therefore, "The chance to mingle with other people is a fundamental part of the consumer experience and social networking sites have become a way in which consumers can interact with one another and retailers" (Paquette, 2013). While social media acts as a platform that enables communication, it is the people who interact on it that act as influencers, and not the technology. The latter simply defines the tangible bounds of the existence of the said platform, but they can easily be pushed and challenged to accommodate growing trends and fashionable ideas that could make statements within these communities. This evolution of a user into an influencer is bridged by a component recognized as - "User Generated Content" (Kang, 2019). Accordingly to Kaplan and Haenlein (Kaplan \& Haenlein, 2016) it as "the sum of all ways in which people make use of social media, usually applied to describe the various forms of media content that are publicly available and created by end users"

Dao (2015) define Social Media as "a group of internet-based applications that build on the ideological and technological foundations of Web 2.0 which allows the creation and exchange of user-generated content." Accordingly to them there are six kinds of interactive platforms to include projects that are collaborative, Blogs and Microblogs, Content Communities, Social Networking Sites, Virtual Game Worlds and Virtual Social Worlds. Social Media has successfully redefined customer engagement, collaboration and community entirely. Certain aspects have indeed been transformed entirely including engagement and microblogging of platforms like Instagram, Facebook and Twitter. Patterson et al (2006) defined engagement as the relationship that the customer shares with an organization with physical, cognitive and emotional presence (Yu, Patterson, \& Ruyter, 2015). Tapscott \& Williams use the term 'Wikinomics' as a movement in their pioneering work, in which 'prosumers' engage in voluble debate and dispute ('blogosphere') and cooperate across hierarchical borders ('wiki-workplace'). Suggest that companies' future lies in the hands of the omnipresent, amorphous mass of self-organized individuals driven by peer production and mass collaboration. Higher education institutions (HEIs) save time, money and all other resources by planning educational exhibitions, fairs and tours virtually to reach out to prospective students. Several International Educational Consultants, Fairs and Exhibitions also provide information to international students who want to study and help them to connect, collaborate and communicate through online, Q\&A sessions and online presentations. Social media care capable of attaining internationalisation with the right support as it is an immensely complex process and seeks adapting to more efficient and practical approaches. It is of the strong belief that international students bring variety of perspective in classrooms enriching the learning environment to an typically homogenous environment (Altman \& Edersberger, 2013). Thus universities rely on social media to attain internationalisation. Social Media marketing campaigns provide efficient and effective use of resources and resource efficiency. Social Media some very essential tools such as cost, speed, personalization and relevance serving as some greatly helpful tools (Choudaga, 2013). The reason behind the shift of universities to move into the social media marketing sphere of action is because of the reliance of the upcoming generations on the digital medium for entertainment, networking and even information; according to the paper titled "Effectiveness of Social Media Marketing: An Experimental Inquiry". For example, one research conducted on the content shared by leading sportspersons on Twitter involved a huge population of their fans discussing their performance, professional achievements and even their personal lives to great extent, amongst an entire community dedicated to this segment of information being transferred. Thus with recreation having such a higher base of users discussing it on platforms such as Facebook and Twitter, Campus recreation marketers need to realise the essence and importance of communicating to these users about their facilities and how they can help deliver a fulfilling recreational experience to these users at a varsity level.

From an international student's point of view, social media offers a communication channel to understand the institute through the eyes of the community, collaborators and communicators on social media. The most ingenuine advantage of is that exorbitant amounts of time and money the International students are not required to spend on travel and research. Traditional media campaigns such as campus events, exhibits, spell bee or any other academic competition require a significant amount of funding unlike social and digital media initiatives. Instead of spreading a long amount of funds universities are now turning to more digitally driven strategies such as training current students to promote the institution of perspective students. Additionally, this also yields a larger reach at a low cost along with being highly creative and relatable. These may include campaign and events hosted on platforms like YouTube, Facebook, Twitter, 
Instagram Etc. The best facet of social media is that it allows the foreign students to customise information and messages in their local language. Digital marketing holds a significant portion of undergraduate and graduate college program marketing budgets in the modern day scenario. Social platforms are play a revolutionary role in digital marketing. Display holds an edge over search tactic of digital marketing in the higher educational institutional markets. Institutions are pushing to adopt and invest in more elaborate display techniques (such as 360 degree videos, AI based interactions etc) that align a more immersive experience with their media strategies.

A case study analysis that studied the trend of HEI's embracing social media (Paladan, 2018) in the marketing strategies attempted to define the potential purposes of institutions turning to social media as a method of running a recruitment campaign, a marketing function or even an outreach program to potential applicants. Universities were also of the belief that creating an online community of existing students, extending it to even alumni and making it a public experience would help cultivate positive perceptions for the institution's legacy and reputation. "Good feedback of peers through social media such as blogs, social networks, forums and other forms are becoming an essential role in the decision making process among young persons."

In a paper titled, "The Effect Of Twitter On College Student Engagement and Grades" the authors, Heiburger and Junco in 2013 (Junco, Heiberger, \& Loken, 2010) states the following - "Through social media, colleges and universities recruit students, engage alumni, develop and sustain institutional academic and athletic brands, connect with students and faculty on and off campus, and manage crises. Student affairs professionals use social media to improve student engagement with academic and extracurricular activities." This paper highlighted the collaborative implementation of the function and supervision student affairs within a University along with a popular social media platform such as Twitter to be able to enhance the purpose of the administrative body within the student council.

In a paper titled "Higher Education Marketing: A Study on the Impact of Social Media on Study Selection and University Choice" it has been found that there are three classes of social media users - a basic class (making up for $29.5 \%$ of the market and engaging in social media exclusively for entertainment purposes), a social class (making up for $40.7 \%$ of the total population, with entertainment and social activities being the major reasons of their presence. They are also highly involved in sharing content of their own, i.e pictures and videos) and the informational class (representing 29.8\% of the market, and as the name suggests they are more involved in seeking information that just engaging in entertainment and socially driven activities). An interesting find that was made explained that the future university students majorly focused on mainstream social media platforms that were used for entertainment and sharing content. Furthermore, a large population of males were considered to be basic users, and a high number of females were observed to be social users. Apart from this, those following science and technology as a lifestyle were seen to be more of basic users while those following a culture and society based curriculum followed a social user-based usage level. However, there is no conclusive evidence from previous studies on the dominance of social media over traditional media for decision making by International students to select an University to study in India.

The research gap in this case is whether students currently are using social media for university and decision-making. It also aims to update current university decision making models which do not specifically indicate internet or social media as information sources during the pre-search and search process.

\section{Research Design Research Design:}

\subsection{Research Questions and Hypothesis}

What is the role, influence and impact of social media on international student's decision to choose a University in India? It includes : Use of social media for search of University / Course, Degree of influence and preference of various social media, Marketing suggestions on site, channels to reach out to international students

Hypothesis:

HO1: Word of mouth creates awareness and preference for universities in decision-making process by International students.

HO2: Social Media is used by International students to make final decision of university

$H O 3$ : Digital marketing influences the final decision making of International student for choice of University

\subsection{Sampling Methods}

\section{Qualitative and Quantitative}

Target Group: International Students and Population Framework -The population consisted of International students enrolled in the first year, in any Indian University offering Post Graduate / Master's degree programmes 


\section{Sampling and Data Collection}

A convenience-based snowball technique was used to reach the students. The students are spread across and have a closed group network which is difficult to get access to. For ease of accessibility and the research being voluntary and non-obtrusive, this technique was helpful. Out of the 340 contacted, 183 voluntarily participated resulting in $76 \%$ response rate. The first 60 who agreed to participate were selected to represent University across four geographical zones in India viz North, South, East and West.

\subsection{Research Instruments}

In-depth interviews (18) and focus group study (48 respondents, 8 groups of 6 each) were conducted to find out factors in social media that inform students about Post-graduate programme in India. The outcome of the in-depth interviews and focus group interviews resulted in XYZ items, which were used to develop a self-administered, structured questionnaire administered to the International students through snowball convenience sampling . A (five-point) ranging from strongly disagreeing to strongly agreeing, coded 1 to 5 respectively was used. Certain relevant demographic variables (gender, age, city of education, country of residence, programme of study). Sections for decision making viz Awareness, Interest, Preference and final decision making was sought for evaluation. Usage of specific media for each stage was determined for the decision to study in India.

The item and construct reliability for all the initial items were ascertained. The Cronbach alpha generated from the output of SPSS was of 0.812, recommended 0.7 (Hair, Black, Babin, \& Anderson, 2010).

\section{Data analysis}

\subsection{Focus Group Discussion}

The factors affecting the decision-making process were recorded as follows : Friends - Defined as the peers of the prospective student - belonging to the same or similar age groups, involved in similar activities and are a source of motivation, healthy competition and bring in high levels of relatability in the relationship they share. Safety and Culture - This factor overlooks the general expectation of a safe and conducive environment for the students and their peers, alike. A healthy and lively student culture along with the desired demographic location brings about a sense of assurance within the decision makers. Financial Reasons - University and higher education are experiences that account for a considerable amount of growth and learning in an individual's life. These experiences come along with a high financial fee as well. Financial reasons are thus, a huge influencing factor affecting the decision making process. Parents' Wish - Being the perspective's primary stakeholders and often the decision makers for important and essential choices in every crucial aspect of life, parents are considered to have substantial influence on the prospective student's perspective on courses and universities. In some situations, it has also been observed that it is the parents who are responsible for financially supporting the ward, and thus as guardians they have the right to inspect and analyse the options. Social Media Reviews - Social media, amongst other platforms boosted by upcoming and developing technology enhance the prospective student's knowledge of what the experience of being a part of the campus and institution is like. Social media presents a reflection of what reality for the institution is like, what the current students see and feel and what lies in store for the applicant who is making the decision to choose the university. Alumni Talks - As individuals who have experienced the best of what the campus and institution have to offer, and have moved on with their lives to achieve success in the following stages - alumni can give testimonies that could significantly bring about a trustworthy and positive perspective within the applicant regarding the university.

\subsection{Survey Analysis}

SPSS Statistics was used for data analysis for this study. Respondents gender : $84 \%$ of the respondents were females and 26\% were females. Age 21- 25, representing countries which include Oman, Saudi Arabia, Japan, United Arab Emirates, Jeddah, Dubai, KSA, South Africa, Qatar, Nigeria, Riyadh, Bahrain

Ha1: Word of mouth doesn't create awareness and preference for University in the international students' university decision-making process. To understand how international students first heard about their university course, frequency analysis was used and result is below in Tabel 1 . 
Table 1. Source of information for university course

Your source of information for university course

\begin{tabular}{|c|c|c|c|c|c|}
\hline & & Frequency & Percentage & $\begin{array}{l}\text { Total } \\
\text { Frequency }\end{array}$ & $\begin{array}{l}\text { Total } \\
\text { Percentage }\end{array}$ \\
\hline \multirow[t]{4}{*}{ Informal } & Family & 35 & 30.4 & 64 & $56 \%$ \\
\hline & Friend & 16 & 13.9 & & \\
\hline & $\begin{array}{l}\text { Other Traditional Information } \\
\text { Sources (not social media) }\end{array}$ & 9 & 7.8 & & \\
\hline & School Counsellor & 4 & 3.5 & & \\
\hline \multirow[t]{6}{*}{ Formal } & Internet Search & 26 & 22.6 & 51 & $44 \%$ \\
\hline & $\begin{array}{l}\text { Newspaper / Magazine / Poster } \\
\text { Advertisement }\end{array}$ & 2 & 1.7 & & \\
\hline & Education Exhibition / Fairs & 4 & 3.5 & & \\
\hline & University Representative & 1 & .9 & & \\
\hline & University Website & 18 & 15.7 & & \\
\hline & Total & 115 & 100.0 & & \\
\hline
\end{tabular}

The result shows that international students first heard about their university course more from Informal sources namely family members, friends and school counsellor than formal sources namely internet search, University Website etc. International students $56 \%$ first hear about their university course from Informal sources and $44 \%$ from formal sources. Further, frequency analysis was used and result is below Table 2.

Table 2. Communication with the University

\begin{tabular}{lll}
\hline & Frequency & Percentage \\
\hline Communicated with the university on traditional media & 100 & $87 \%$ \\
Not communicated with the university on traditional media & 15 & $13 \%$
\end{tabular}

The result shows that majority students (87\%) communicated with the university on traditional media during university search while some students $(13 \%)$ did not contact or interacted with the university on traditional media during university search.

Thus, Ho1 gets accepted, emphasizing the role of personal, word of the mouth media for creating initial awareness.

Ha2: Social Media isn't used by International students to make final decision of university

Descriptive Statistics was used and result is below in Table 3:

Table 3. Decsion to select the University

\begin{tabular}{llllll}
\hline & $\mathrm{N}$ & Degree & Agree & $\begin{array}{l}\text { Mean } \\
\text { 4-point } \\
\text { scale }\end{array}$ & on $\begin{array}{l}\text { Std. } \\
\text { Deviation }\end{array}$ \\
\hline $\begin{array}{l}\text { With increasing social media clutter, social media } \\
\text { didn't enable you take a final decision for University } \\
\text { selection }\end{array}$ & 106 & $\begin{array}{l}41 \\
(38 \%)\end{array}$ & $\begin{array}{l}74 \\
(62 \%)\end{array}$ & 2.72 & 0.825 \\
\hline
\end{tabular}


Results show that international students held that information on social media didn't enable them to make a final decision for University selection. Mean of response is 2.72 on 4 point scale which shows that international students accepted that even increasing social media clutter, social media didn't enable them to take a final decision for University selection. $74(62 \%)$ respondents agree that with increasing social media clutter, social media didn't enable you to make a final decision for University selection while only 41 (38\%) degree with the same.

To study whether Social information can be complimentary for final decision for University selection, Descriptive Statistics was used and result is in Table 4.

Table 4. Social media and university selection

Descriptive Statistics

\begin{tabular}{llllll} 
& Disagree & Agree & N & Mean & $\begin{array}{l}\text { Std. } \\
\text { Deviation }\end{array}$ \\
\hline $\begin{array}{l}\text { Do you believe social media helps prospective students } \\
\text { to select University in India? }\end{array}$ & $\begin{array}{l}28 \\
(24 \%)\end{array}$ & $87(76 \%)$ & 115 & 3.04 & 0.799 \\
$\begin{array}{l}\text { Would you endorse social media to your friends for } \\
\text { selection of University in India? }\end{array}$ & $\begin{array}{l}36 \\
(31 \%)\end{array}$ & $79(69 \%)$ & 115 & 2.84 & 0.894 \\
\hline
\end{tabular}

The result indicated that international students believe social media helps prospective students to select universities in India. Mean on the four-point scale is 3.04 and $87(76 \%)$ respondents agree with it and only 28 (24\%) degree with it. International students endorse social media use to their friends to select a university. Mean on the four-point scale is 2.84 and $79(69 \%)$ respondents agree with it and only $36(31 \%)$ degree with it. To understand impact of social media on selection of university, Descriptive Statistics was used and result is in Table 5.

Table 5. Decision of Univerity and social media

Descriptive Statistics

For each statement listed below, indicate the impact on your selection of your university (scale of 1-4, 1 being least important and 4 being most important)

least most Std.

\begin{tabular}{lllllll} 
& important & important & N & Mean & Deviation \\
\hline $\begin{array}{l}\text { For my decision of University, Social media } \\
\text { additional information }\end{array}$ & $46(42 \%)$ & 115 & 2.66 & 1.075
\end{tabular}

$69(58 \%)$

For my decision of University, Social Media 51 (44\%)

$\begin{array}{lll}115 & 2.59 & 0.972\end{array}$

helped me make a decision

$64(56 \%)$

For my decision of University, Social Media had $\quad 53(46 \%) \quad 62(54 \%) \quad 115 \quad 2.56 \quad 0.957$ some influence on my university decision

The result shows that international students reported that social media provided them additional information for university decision in which the mean of four point scale is 2.66 and $69(58 \%)$ students rated most important and 46 
(42\%) reported least important. International students reported that Social media provided them additional information for university decisions in which the mean of four point scale is 2.59 and $64(56 \%)$ students rated most important and $51(44 \%)$ reported least important. International students also reported that Social media had some influence on university course decisions in which the mean of four point scale is 2.56 and $62(54 \%)$ students rated most important and $53(46 \%)$ reported least important. Thus, $\mathrm{Ha} 2$ gets accepted. Social Media is not used by International students to final choice decisions for selection of university.

Ha3 : Digital marketing doesn't influence the final decision making of International student for choice of University

To understand whether Digital Marketing information sources influenced international student on final decision for University selection, Descriptive Statistics was used and result is in Table 6.

Table 6. Information sources influencing decision-making

Descriptive Statistics

On a scale of 1 - 4 ( 1 being not at all and 4 being most important), which of the following information sources influenced you most in your decision-making?

Std.

\begin{tabular}{lccc}
\hline Internet Search & 114 & 3.18 & 0.885 \\
University Website & 114 & 3.05 & 0.939 \\
Family member & 113 & 2.75 & 1.048 \\
Friend & 113 & 2.71 & 0.997 \\
Counsellor & 112 & 2.02 & 1.082 \\
Education Guide / Directory & 112 & 2.00 & 0.968 \\
University Representative & 113 & 1.97 & 0.986 \\
Other Traditional Information Sources & 112 & 1.91 & 1.09 \\
Education Exhibition/Fairs & 112 & 1.77 & 0.968 \\
Scholarship Agency in my country & 112 & 1.58 & 0.946 \\
Newspaper Advertisement & 112 & 1.52 & 0.816 \\
Foreign Embassy & 112 & 1.43 & 0.824
\end{tabular}

The results clearly show that Internet search followed by University websites (put together classified as Digital Marketing) is preferred for decision making. Thus, Ho3 gets accepted.

\section{Conclusion}

International students depend on social media for additional information. This stresses the role of Integrated Marketing Communications for University marketing. With increasing media clutter it's absolutely essential to ensure the clarity of social media messaging and selection of appropriate social media tools to reach the students and effectively use it for decision making. Social media with respect to word of mouth and influencer marketing can be leveraged to help the students' decision-making process.

This research paper provides vital information to the role of social media for students who are opting to study away from their home country at Indian Universities. This study recognizes the decision-making process and the most important media factors at a specific stage of decision making. This information can support the university marketing 
team and the management to plan approaches to entice and create preferences of their University amongst international students. These research findings are consistent with other findings of the role of social media as a crucial and integrating part of the marketing strategies.

One of the findings of this study is that word of mouth and informal sources are critical to creating awareness. Thus, it is crucial to use influencer marketing ideas to encapsulate the real-time experiences of the existing students and alumni in an informal messaging format. Leveraging the opinion and voice of existing happy customers viz 'parent' and 'relatives in the host country', who being the most important stakeholders in the decision making process, will be pivotal in creating a pull. Accordingly, university brand marketing and management teams need to leverage the opinions and voices of these stakeholders in their internet marketing and digital plan to ensure a 'single unified voice' for the brand communication. The social media thus has to generate conversation on aspects relating to decision making. The messaging and marketing have to be in sync with the objectives sought by the international students for selection of University. There is therefore a need for the University to invest in quality messaging.

The focus group discussion also throws light on the language preference of parents during the search process due to the presence of diverse nationalities opting to study in India. The financial assistance, tie-ups, scholarship provided by the University also emerged as a focal point for decision making that social media tools need to integrate in the communication strategies.

The next important factor that the focus group discussion throws light on is the Safe learning environments for students that is disseminated as information through the informal sources to the prospective students. This could be intervened within the messaging and thus would be a great marketing tool for Indian Universities attracting International students.

The study also reveals that 'accepting and warm culture' plays an important role in the selection of universities by International students. Emphasis by universities should be on the friendly-warm culture. "A home-away from-home".

\section{Limitations}

The sample is small, and derived from International students presently enrolled in any university in India. Previous students have not been covered. Another limitation is that the study is not focused on any specific stream, or degree opted for. The differing needs and views of these students is not captured.

\section{References}

(n.d.). Retrieved May 11, 2020, from http://saviance.com/whitepapers/digital-marketing-in-educational-instituions/

(n.d.). Retrieved May 11, 2020, from http://www.globaled.us/plato/resources.html

(n.d.). Retrieved May 11, 2020, from https://pib.gov.in/newsite/mainpage.aspx

Altmann, A. (2013). Universities in change. New York, NY: Springer. https://doi.org/10.1007/978-1-4614-4590-6

Bayne, K. S. (2011). Effectiveness of Social Media Marketing: An Experimental Inquiry on College Students' Awareness of, Interest in, and Intention to Participate in a Campus Recreation Special Event (Unpublished master's thesis). Georgia State University.

Brodie, R. J., Ilic, A., Juric, B., \& Hollebeek, L. (2013). Consumer engagement in a virtual brand community: An exploratory analysis. Journal of Business Research, 66(1), 105-114. https://doi.org/10.1016/j.jbusres.2011.07.029

Bruce, C., Davis, K., Hughes, H., Partridge, H., \& Stoodley, I. (Eds.). (2014). Information Experience: Contemporary Perspectives. Bingley: Emerald Group Publishing Limited. https://doi.org/10.1108/S1876-0562_2014_0000010001

Casaló, L. V., Flavián, C., \& Guinalíu, M. (2008). Promoting Consumer's Participation in Virtual Brand Communities: A New Paradigm in Branding Strategy. Journal of Marketing Communications, 14(1), 19-36. https://doi.org/10.1080/13527260701535236

Chatfield, H. K., Lee, S. J., \& Chatfield, R. E. (2012). The Analysis of Factors Affecting Choice of College: A Case Study of University of Nevada Las Vegas Hotel College Students. Journal of Hospitality \& Tourism Education, 24(1), 26-33. https://doi.org/10.1080/10963758.2012.10696659

Choudaha, R. (2012). Trends in International Student Mobility. World Education News \& Reviews, 25(2).

Constantinides, E., \& Stagno, M. C. (2011). Potential of the social media as instruments of higher education marketing: A segmentation study. Journal of Marketing for Higher Education, 21(1), 7-24. https://doi.org/10.1080/08841241.2011.573593 
Contributor, G. (2012, December 18). How are Colleges Using Social Media to Attract Students? Retrieved May 11, 2020, from https://socialmediaweek.org/blog/2012/12/how-are-colleges-using-social-media-to-attract-students/

Cubillo, J. M., Sánchez, J., \& Cerviño, J. (2006). International students' decision-making process. International Journal of Educational Management, 20(2), 101-115. https://doi.org/10.1108/09513540610646091

Dao, D. V. (2015). Social Media Classification Scheme in Online Teaching and Learning Activities: A Consideration for Educators. International Journal of Education and Social Science, 2(4).

Definition of International Student. (n.d.). Retrieved May 11, 2020, from https://www.wpunj.edu/cie/definition-of-international-student.html

International Journal of Communication. (n.d.). Retrieved May 11, 2020, from https://ijoc.org/index.php/ijoc/issue/view/2

International Students. (n.d.). Retrieved May 11, 2020, from https://admission.usc.edu/apply/international-students/

Ivy, J. (2010). Choosing futures: Influence of ethnic origin in university choice. International Journal of Educational Management, 24(5), 391-403. https://doi.org/10.1108/09513541011055965

Junco, R., Heiberger, G., \& Loken, E. (2010). The effect of Twitter on college student engagement and grades. Journal of Computer Assisted Learning, 27(2), 119-132. https://doi.org/10.1111/j.1365-2729.2010.00387.x

KangView full profile >, A., Kang, A., More by this author:What is Pragmatic MarketingEverything You Need to Know About Performance MarketingWhat is Agile Marketing: Everything You Need to Know, \& Author:, M. (n.d.). What Is User Generated Content And How It Is Relevant? Retrieved June 28, 2020, from https://www.business2community.com/content-marketing/what-is-user-generated-content-and-how-it-is-relevan $\mathrm{t}-02175516$

Kaplan, A. M., \& Haenlein, M. (2016). Higher education and the digital revolution: About MOOCs, SPOCs, social media, and the Cookie Monster. Business Horizons, 59(4), 441-450. https://doi.org/10.1016/j.bushor.2016.03.008

Mittler, J. N., Martsolf, G. R., Telenko, S. J., \& Scanlon, D. P. (2013). Making Sense of "Consumer Engagement" Initiatives to Improve Health and Health Care: A Conceptual Framework to Guide Policy and Practice. Milbank Quarterly, 91(1), 37-77. https://doi.org/10.1111/milq.12002

OECD Annual Report (Publication). (2003).

Paladan, N. N. (2018). Higher Education Institutions Embracing Digital \& Social Media Marketing: A Case of Top 25 Universities in Asia \& Africa. SSRN Electronic Journal. https://doi.org/10.2139/ssrn.3347018

Paquette, H. (2013). Social Media as a Marketing Tool: A Literature Review (Unpublished doctoral dissertation). University of Rode Island.

Parasuraman, A. (2000). Technology Readiness Index (Tri). Journal of Service Research, 2(4), 307-320. https://doi.org/10.1177/109467050024001

Phang, S. L. (2013). Factors influencing international students' study destination decision abroad (Unpublished master's thesis). University of Gothenburg.

Qualman, E. (2009). Socialnomics: How Social Media Transforms the Way We Live and Do Business. New Jersey: Wiley \& Sons.

Social Media Usage Statistics 2012. (2012, December 19). Retrieved May 11, 2020, from https://www.brandwatch.com/blog/how-we-use-social-highlights-from-the-social-media-report-2012/

Thorton, K. C. (2017). Understanding the role of social media on a student's college choice process and the implications on a university's enrollment and marketing strategies (Doctoral dissertation, Louisiana Tech University). Ann Arbor: Proquest.

Yu, T., Patterson, P., \& Ruyter, K. D. (2015). Converting service encounters into cross-selling opportunities. European Journal of Marketing, 49(3/4), 491-511. https://doi.org/10.1108/EJM-10-2013-0549

Zhou, M., \& Zang, F. (2018). Factors affecting Chinese Students' choice of studying in Sweden (Unpublished master's thesis). Uppsala University. 